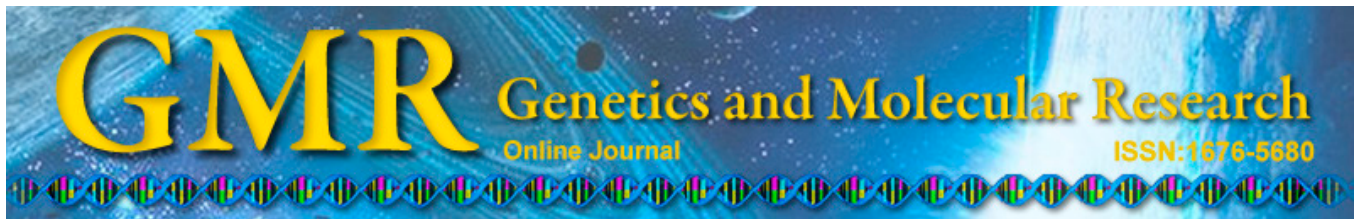

\title{
Isolation, molecular cloning, and characterization of a novel porcine lymphotoxin beta receptor gene
}

\author{
Y.Y. Zhang ${ }^{1 *}$, S.Y. Wang ${ }^{2 *}$, Y.W. Miao ${ }^{2 *}$, W.Z. Li ${ }^{2 *}$, Q.L. Zhang ${ }^{3}$, \\ F.Q. $\mathrm{Li}^{4}$, L.X. Liu ${ }^{5}$, H.L. Huo ${ }^{5}$ and J.L. Huo ${ }^{2}$
}

${ }^{1}$ Teaching Demonstration Center of the Basic Experiments of Agricultural Majors, Yunnan Agricultural University, Kunming, Yunnan, China

${ }^{2}$ Faculty of Animal Science and Technology, Yunnan Agricultural University,

Kunming, Yunnan, China

${ }^{3}$ College of Animal Science and Veterinary Medicine, Jilin University, Changchun, Jilin, China

${ }^{4}$ Department of Biotechnology, Neijiang Vocational \& Technical College, Neijiang, Sichuan, China ${ }^{5}$ Department of Husbandry and Veterinary, Yunnan Vocational and Technical College of Agriculture, Kunming, Yunnan, China

*These authors contributed equally to this study.

Corresponding author: J.L. Huo

E-mail: jinlonghuo973@163.com

Genet. Mol. Res. 13 (4): 9766-9776 (2014)

Received October 23, 2013

Accepted March 19, 2014

Published November 27, 2014

DOI http://dx.doi.org/10.4238/2014.November.27.4

\begin{abstract}
The lymphotoxin beta receptor (LT $\beta R$ ) is a member of the tumor necrosis factor family of receptors (TNFR). It plays a role in regulating lymphoid organogenesis and homeostasis of the immune system. In the present study, the full coding region of a putative $L T \beta R$ gene of Sus scrofa was amplified by reverse transcription-polymerase chain reaction (RT-PCR) and cloned for the first time (accession Nos. JX457347 and AFU74012). In addition, analysis of the tissue expression profile was carried out via RT-PCR. The full-length coding region of
\end{abstract}


porcine $L T \beta R$ had 1266 nucleotides (molecular weight, $45.61 \mathrm{kDa}$; $\mathrm{pI}$, 5.71 ) and encoded 421 amino acids. Bioinformatic prediction indicates that LT $\beta$ R belongs to the TNFR superfamily and contains a TNFR domain. The sequence homology analysis revealed that the amino acid sequences of $S$. scrofa LT $\beta$ R had 82.9, 82.4, 81.3, 80.5, 78.7, 74.6, and $73.0 \%$ identity with those of Equus caballus, Canis lupus, Ailuropoda melanoleuca, Oryctolagus cuniculus, Bos taurus, Mus musculus, and Homo sapiens, respectively. The phylogenetic tree based on the amino acid sequences of $L T \beta R$ from 8 species revealed that $S$. scrofa was more closely related to E. caballus, C. lupus, and A. melanoleuca. RT-PCR analysis showed that the porcine $L T \beta R$ gene was differentially expressed (e.g., high, moderate, low, or nonexistent) in various tissues (e.g., prostate, pituitary, brainstem, and esophagus, respectively). This may be related to differences in the regulation of LT $\beta$ R in the different tissues.

Key words: Lymphotoxin beta receptor (LT $\beta R)$; Sus scrofa; Tumor necrosis factor family of receptors (TNFR);

Tissue expression analysis

\section{INTRODUCTION}

The lymphotoxin beta receptor (LT $\beta R$ ) is a member of the tumor necrosis factor (TNF) family, which includes ligands and receptors that are important regulatory elements in the immune system (Smith et al., 1994). LT $\beta$ R can recognize the major cell surface LT- $\alpha / \beta$ complex (Crowe et al., 1994) and is expressed on the surface of most cell types (e.g., epithelial and myeloid lineages), with the exception of T and B lymphocytes. When bound to TNF-like cytokines, the receptors of TNF (TNFRs) trigger multiple cellular responses, including cell death and growth, that regulate inflammatory and immune defenses (Beutler and van Huffel, 1994; Tracey and Cerami, 1994). LT $\beta$ R does not only help trigger apoptosis and lead to the release of cytokine interleukin 8 , but it is also essential for development and organization of the secondary lymphoid organs and chemokine release (Chang et al., 2002). The TNF family members such as LT $\alpha / \beta$, TRAF5 (Nakano et al., 1996), TRAF3 (VanArsdale et al., 1997; Marsters et al., 1997; Wu et al., 1999), TRAF2 (Vondenhoff et al., 2007), and LTGHT (Rooney et al., 2000; Gill et al., 2007) can be directly associated with LT $\beta R$ and other receptors immediately after ligand binding, implicating their role in signaling. The TNFR superfamily members have been found to contain 6 conserved cystein domains of approximately 110 to 160 amino acids (AAs) in their N-terminal regions (Armitage, 1994), which allows for the formation of an extended rod-like structure that is responsible for ligand binding (Banner et al., 1993).

Many reports indicate that LT $\beta$ R pathways actively contribute to effector immune responses. The lymphotoxin- $\alpha \beta / \mathrm{LT} \beta \mathrm{R}$ system plays an important role in chronic inflammation, autoimmunity, cell death, and cancer development (Remouchamps et al., 2011). LTßR activation on mouse macrophages is involved in the control of proinflammatory cytokine and mediator expression via activation of a signaling pathway that controls exacerbating inflammatory cytokine production (Wimmer et al., 2013). 
Although LT $\beta R$ is essential for development and organization of the immune system, sequencing of the porcine $L T \beta R$ gene has not yet been conducted. Thus, in the current study, based on the abundant bioinformatic resources and software tools available, we initially isolated the full-length coding sequence of the porcine $L T \beta R$ gene. Subsequently, we conducted a bioinformatic analysis based on the data obtained. Finally, we examined the expression patterns of $L T \beta R$ in 31 tissues by semi-quantitative reverse transcription-polymerase chain reaction (RT-PCR). This study will aid investigations into the role of porcine LT $\beta R$ in immune function and development.

\section{MATERIAL AND METHODS}

\section{Sample collection, RNA extraction, and complementary DNA (cDNA) synthesis}

All experimental procedures were approved by the Yunnan Agricultural University Committee of Laboratory Animal Care. Fresh tissue samples were obtained from 10 male pigs (Sus scrofa). Thirty-one tissues, including the brain, cerebellum, hypothalamus, brainstem, spinal cord, heart, liver, spleen, lung, kidney, stomach, pancreas, esophagus, duodenum, jejunum, ileum, colon, cecum, rectum, testis, epididymis, sublingual gland, submandibular gland, thyroid, adrenal gland, thymus, pituitary, prostate gland, lymph node, skin, and muscle, were immediately dissected and frozen in liquid nitrogen until RNA extraction. Total RNA was extracted using the RNAiso Plus kit (TaKaRa, Dalian, China) according to manufacturer instructions. To eliminate genomic DNA contamination, total RNA was digested via RNasefree DNase I (TaKaRa). Four micrograms of RNA was reverse-transcribed with oligo $(\mathrm{dT})_{18}$ primer and the PrimeScript High-Fidelity RT-PCR Kit (TaKaRa). Reverse transcription was verified on $2 \%$ agarose gel electrophoresis containing ethidium bromide. The cDNA concentrations were also measured for different types of tissues using the UV-Vis Spectrophotometer (NanoDrop 2000).

\section{Isolation of the porcine $L T \beta R$ gene}

The $L T \beta R$ sequences for the highly homologous pig-expressed sequence tag (accession Nos. DV937051, EV964894, and GB610053) were used to design a primer pair by the Primer Premier 5.0 software. The primer set was as follows: 5'-ACGTCCAGGCCTCCCATCTT-3' (forward) and 5'-GCTTCCTTTCTCCTGGCTTCTC-3' (reverse).

RT-PCR with the primer set was performed to isolate the complete coding sequence of the $L T \beta R$ gene by employing the cDNAs obtained from the different tissues listed above. The $25-\mu \mathrm{L}$ reaction system was: $2.0 \mu \mathrm{L} 25 \mathrm{ng} / \mu \mathrm{L}$ cDNA, $2.0 \mu \mathrm{L} 2.5 \mathrm{mM}$ mixed deoxyribonucleotide triphosphates (dNTPs), $2.5 \mu \mathrm{L} 2 \mathrm{X}$ GC buffer I (TaKaRa), $0.5 \mu \mathrm{L} 10 \mu \mathrm{M}$ forward primer, $0.5 \mu \mathrm{L} 10 \mu \mathrm{M}$ reverse primer, $0.25 \mu \mathrm{L} 5 \mathrm{U} / \mathrm{L}$ Taq DNA polymerase (TaKaRa), and $17.25 \mu \mathrm{L}$ sterile water. The PCR program was initiated with denaturation at $94^{\circ} \mathrm{C}$ for $2 \mathrm{~min}$; followed by 34 cycles of $94^{\circ} \mathrm{C}$ for $30 \mathrm{~s}, 60^{\circ} \mathrm{C}$ for $45 \mathrm{~s}$, and $72^{\circ} \mathrm{C}$ for $2 \mathrm{~min}$; a $72^{\circ} \mathrm{C}$ extension for 10 min, and, finally, $4^{\circ} \mathrm{C}$ to terminate the reaction. The commercial fluorometric method was utilized to bidirectionally sequence the PCR products. Then, the products were cloned into the pMD18-T vector to obtain the independent clone. Five independent clones were selected for sequencing. 


\section{Bioinformatic analysis}

Sequences were examined and edited by using the DNAStar software. The complete coding sequence of the porcine LTRR gene has been deposited into the NCBI database. With the use of the National Center for Biotechnology Information (NCBI) online software (http:// www.ncbi.nlm.nih.gov), we aligned the sequences for analysis.

The molecular weight $(\mathrm{Mw})$ and theoretical isoelectric point $(\mathrm{pI})$ were calculated by Compute Mw/pI (http://web.expasy.org/compute_pi/). The signal peptide was predicted using the SignalP 4.1 server (http://www.cbs.dtu.dk/services/SignalP/). Protein transmembrane topology analysis was conducted using the TMHMM Server v2.0 online software (http://www. cbs.dtu.dk/services/TMHMM-2.0/; Moller et al., 2001).

The prediction and analysis of proteins were performed using the Conserved Domain Architecture Retrieval Tool of BLAST on the NCBI server (http://www.ncbi.nlm.nih. gov/BLAST). For predictions of the secondary structures of deduced AA sequences, we utilized SOPMA (http://npsa-pbil.ibcp.fr/). The three-dimensional structures of the LT $\beta R$ protein were predicted by AA homology modeling using the online server at http://www. expasy.org/swissmod/SWISSMODEL.html (Guex and Peitsch, 1997; Schwede et al., 2003; Arnold et al., 2006).

Homology analysis based on the LT $\beta R$ AA sequences of S. scrofa, Equus caballus, Canis lupus, Ailuropoda melanoleuca, Oryctolagus cuniculus, Bos taurus, Mus musculus, and Homo sapiens species was conducted using the MEGA 5 Software. To construct a phylogenetic tree based on LT $\beta$ R AA sequences via neighbor-joining, the CLUSTAL X 2.0 and MEGA 5 programs were utilized. The bootstrap method (with 10,000 replications) was used to assess the statistical significance of groups within the phylogenetic trees.

\section{Expression profile analysis via RT-PCR}

We conducted semi-quantitative RT-PCR to determine $L T \beta R$ mRNA expression in 31 porcine tissues. The housekeeping gene $18 S$ (AY265350) was used as the positive control. The primers used for the testing control gene were as follows: 5'-GGACATCTAAGG GCATCACAG-3' (forward) and 5'-AATTCCGATAACGAACGAGACT-3' (reverse). The porcine $L T \beta R$ primer set used to perform semi-quantitative RT-PCR was the same as that used for the above-mentioned isolation RT-PCR.

\section{RESULTS}

\section{Sequence and identification analysis}

In analyzing the sequence alignment, we found that the $L T \beta R$ gene sequence obtained in the current study was not homologous to any of the previously identified swine genes. The PCR product of porcine $L T \beta R$ was 1399 bp in length, which included a 1266-bp coding region sequence, partial 5'-untranslated regions (UTRs), and 3'-UTRs (Figure 1). The coding region sequence encoded 421 AAs (Figure 2). The sequences of the porcine $L T \beta R$ gene have been deposited into the NCBI database (i.e., accession Nos. JX457347 and AFU74012 for nucleotides and AAs, respectively). 


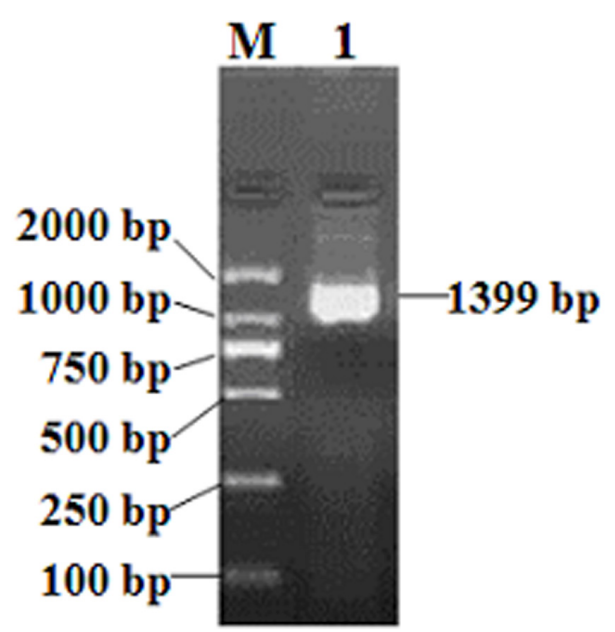

Figure 1. Reverse transcription-polymerase chain reaction (RT-PCR) results for porcine lymphotoxin beta receptor $(L T \beta R)$ gene. Lane $M=$ DL2000 DNA marker; lane $1=$ RT-PCR product of the LTBR gene.

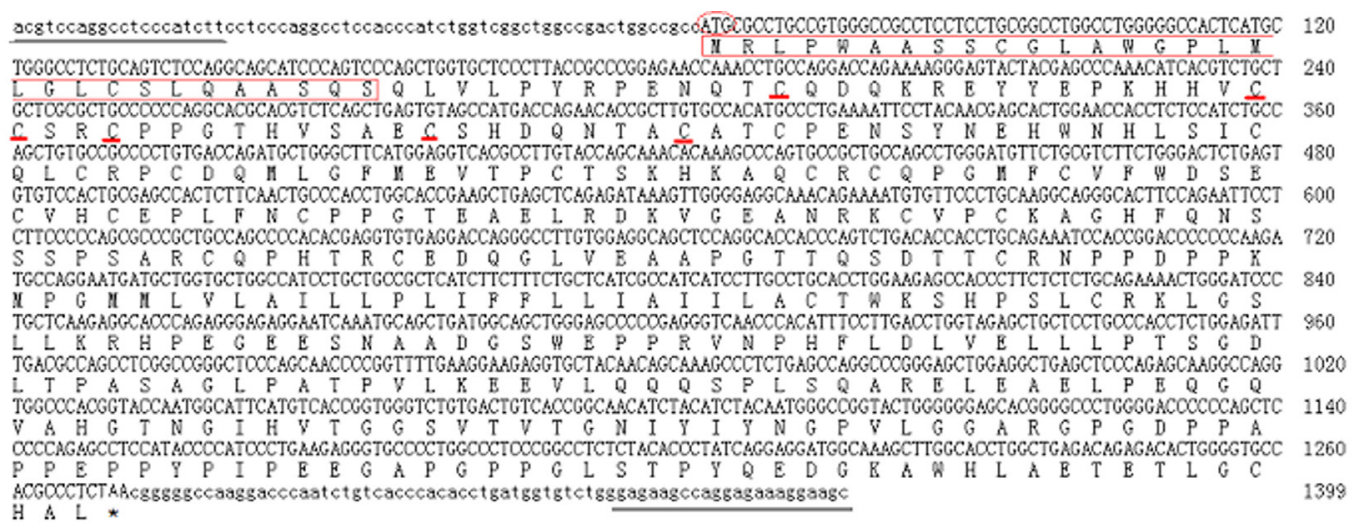

Figure 2. Complete complementary DNA and amino acid sequences of the protein encoded by LTBR (accession Nos. for nucleotides and amino acids: JX457347 and AFU74012, respectively). ATG, start codon; TAG, stop codon; capital letters, complete coding DNA and amino acid sequences; underlining nucleotide sequences, primers; amino acid sequences in red box, signal peptide; underlining amino acids, six conserved cysteins in TNFR domain.

\section{Bioinformatic analysis}

The Mw of porcine LT $\beta R$ was $45.61 \mathrm{kDa}$ and the $\mathrm{pI}$ was 5.71. The bioinformatic analysis indicated that LT $\beta R$ was a potential membrane intrinsic protein, and the forward $30 \mathrm{AAs}$ comprised the signal peptide (Figure 3). The signal peptide was marked with a box in Figure 2. The Conserved Domain Architecture Retrieval Tool of BLAST indicated that porcine LT $\beta R$ belongs to the TNFR superfamily and contains a TNFR domain (Figure 4).

SOPMA predicted that the secondary structure of deduced LT $\beta R$ contained 115 AA alpha helices, 48 AA extended strands, 27 AA beta turns, and 231 AA random coils (Figure 5). The homology modeling of LT $\beta R$ was performed to estimate its three-dimensional structure, which was predicted based on the existing structures of the 4fhq complex (Altschul et al., 1997; Figure 6). 


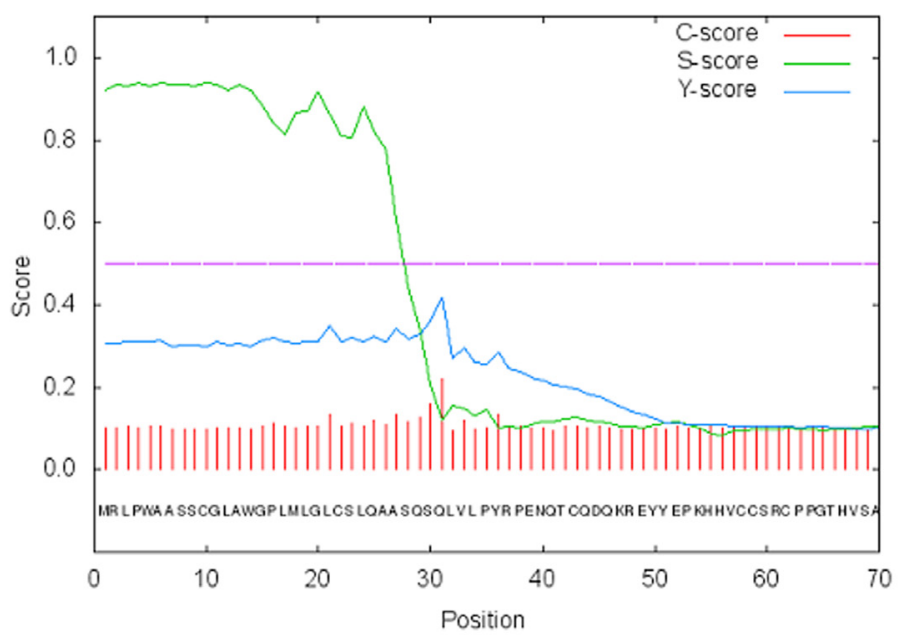

Figure 3. Signal peptide prediction of the protein encoded by porcine $L T \beta R$.

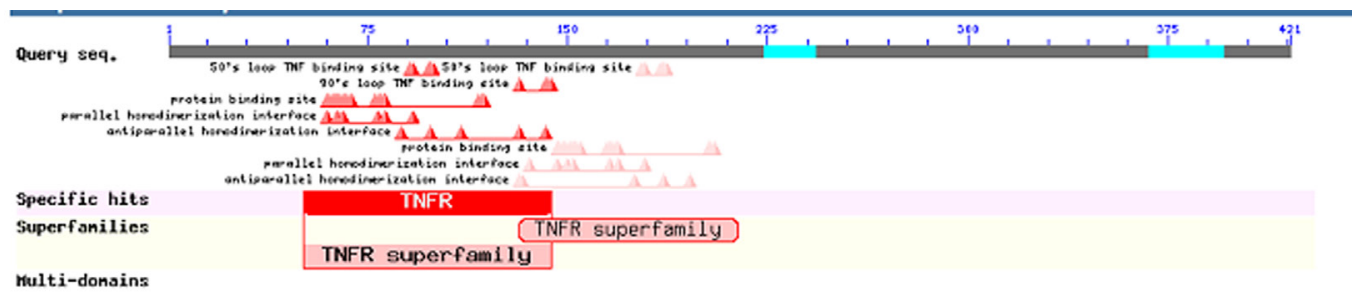

Figure 4. Putative conserved domains of the protein encoded by porcine $L T \beta R$.

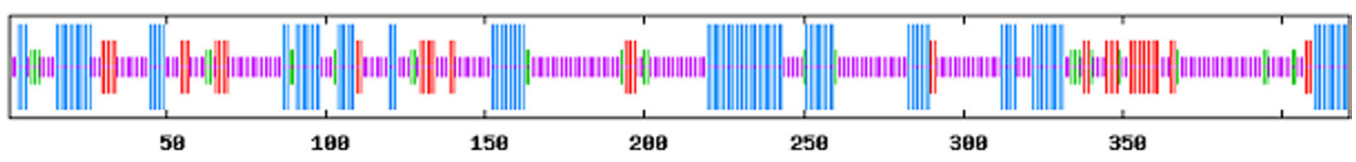

Figure 5. Secondary structure of the LT $\beta$ R protein predicted with the self-optimized prediction method with alignment. The longest, second longest, second shortest, and shortest vertical lines indicate helices, extended strands, beta turns, and random coils, respectively.

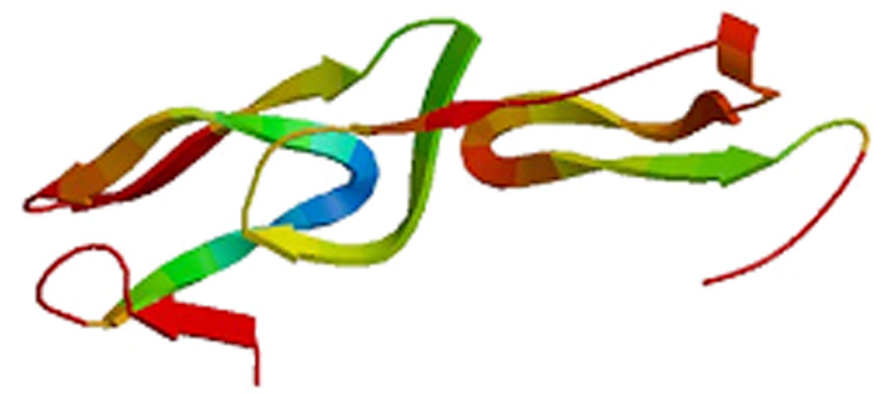

Figure 6. Homology modeling of LT $\beta R$ (47-134 amino acids) based on the crystal structure of DIMER domain (4fhq: 35-227 amino acids). 
The AA sequences of $S$. scrofa (AFU74012) LT $\beta R$ in this study had 82.9, 82.4, 81.3, 80.5, 78.7, 74.6, and 73.0\% identity with those of E. caballus (XP_001492220), C. lupus (XP_543855), A. melanoleuca (XP_002922296), O. cuniculus (NP_001254634), B. taurus (AAI49640), M. musculus (NP_034866), and H. sapiens (NP_002333), respectively. There were many polymorphisms found in the coding regions of the $L T \beta R$ gene between $S$. scrofa and other species (Figure 7). However, the 6 conserved cysteins in the TNFR domain were conserved in the 8 species used in the study.

The phylogenetic tree constructed based on the LT $\beta$ R AA sequences using the neighbor-joining method showed that $S$. scrofa was more closely related to E. caballus, C. lupus and A. melanoleuca (Figure 8).

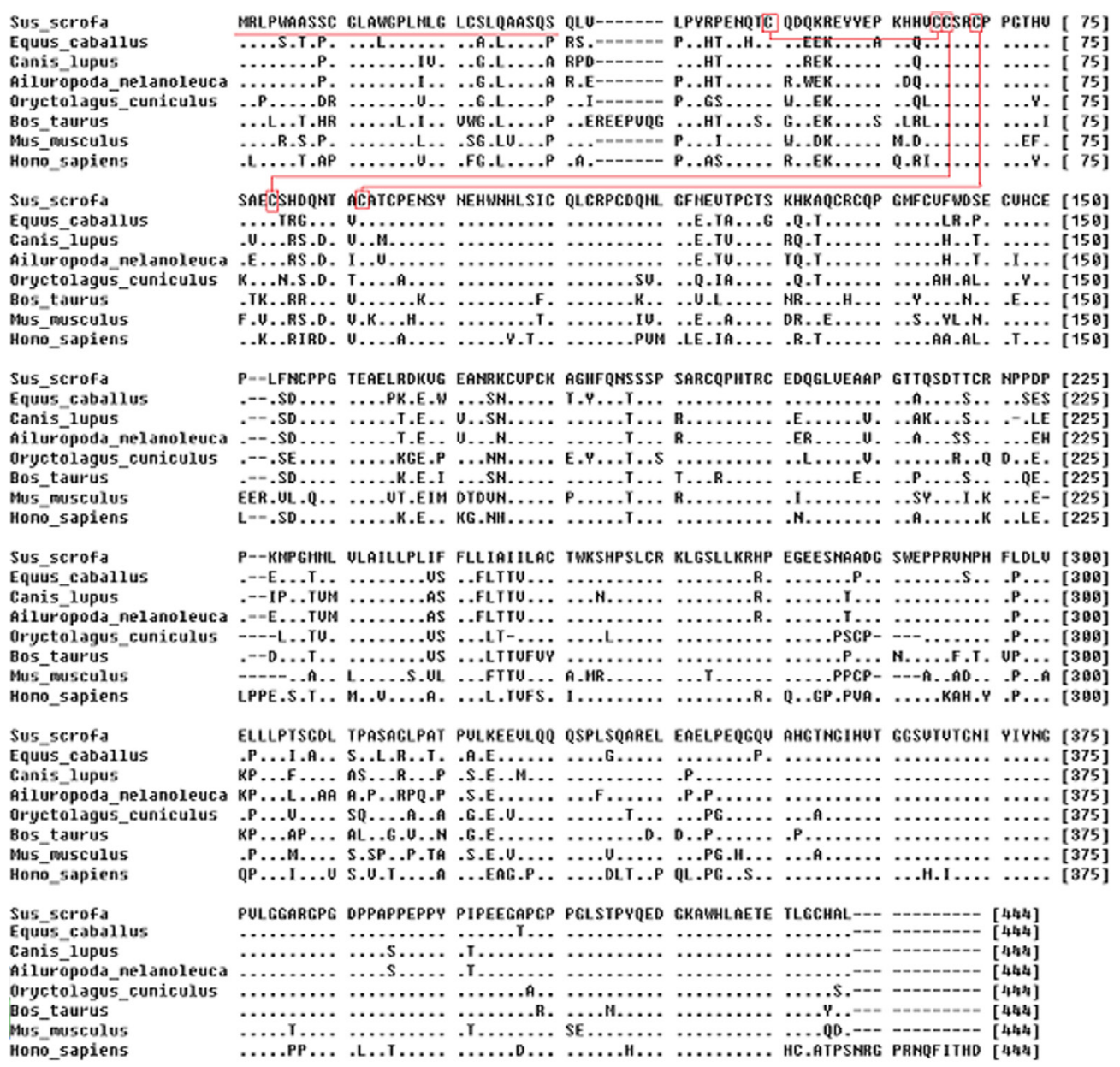

Figure 7. Alignments of the LTßR protein sequences between Sus scrofa and seven other species from Equus caballus, Canis lupus, Ailuropoda melanoleuca, Oryctolagus cuniculus, Bos taurus, Mus musculus, and Homo sapiens. Sequence underlined, signal peptide region; amino acids with box and line, six conserved cysteins and disulfide bonds in N-terminal part. 


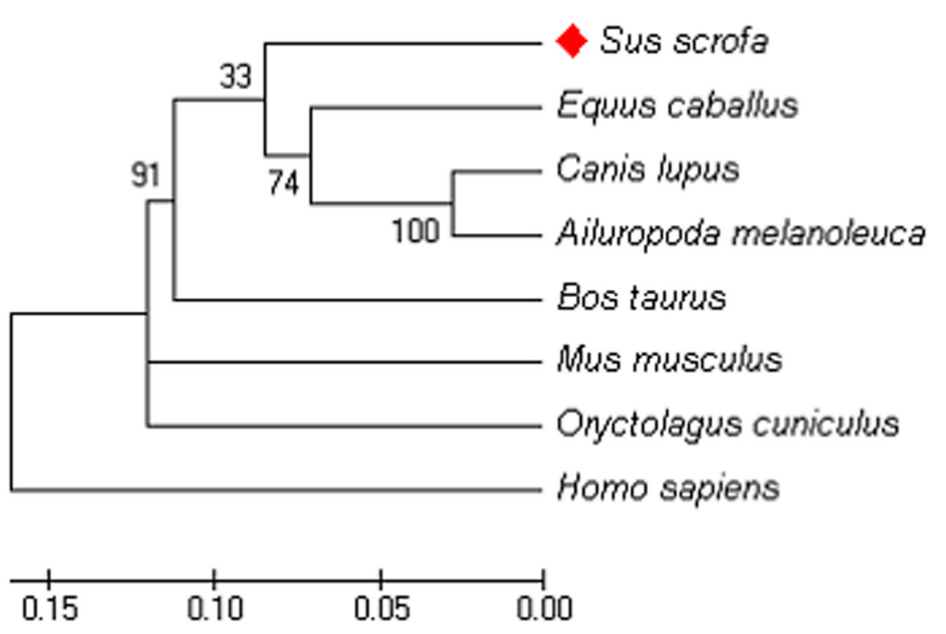

Figure 8. Phylogenetic tree based on eight kinds of LTßR protein sequences from Sus scrofa, Equus caballus, Canis lupus, Ailuropoda melanoleuca, Oryctolagus cuniculus, Bos taurus, Mus musculus, and Homo sapiens.

\section{Tissue expression profile analysis of $L T \beta R$}

According to RT-PCR, $L T \beta R$ mRNA was widely expressed in the tissues examined. Expression was high in the prostate, submandibular, and adrenal glands; moderate in the pituitary, kidney, cerebellum, duodenum, brain, testis, thyroid, muscle, liver, lung, sublingual gland, heart, spinal cord, epididymis, thymus, and lymph node; minimal in the brainstem, hypothalamus, skin, jejunum and cecum; and almost nonexistent in the esophagus, rectum, pancreas, colon, ileum, spleen, and stomach (Figure 9).

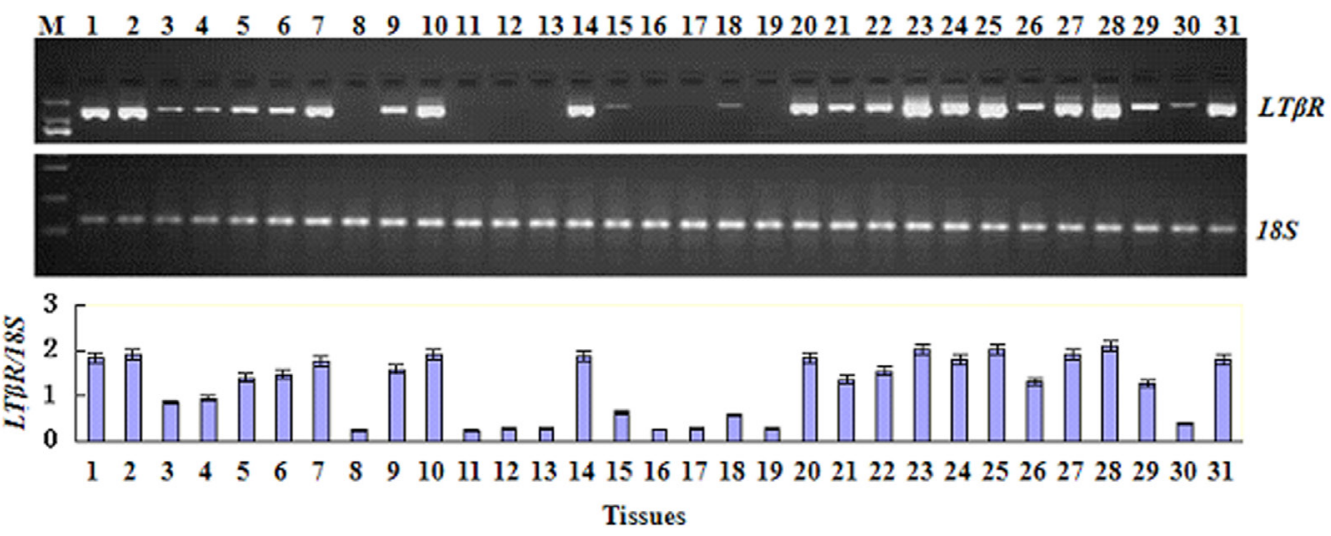

Figure 9. Tissue transcription profile of the porcine $L T \beta R$ gene. Lane $M=$ DL2000 DNA marker; lane $1=$ brain; lane 2 = cerebellum; lane 3 = hypothalamus; lane 4 = brainstem; lane $5=$ spinal cord; lane $6=$ heart; lane 7 = liver; lane $8=$ spleen; lane $9=$ lung; lane $10=$ kidney; lane $11=$ stomach; lane $12=$ pancreas; lane $13=$ esophagus; lane 14 = duodenum; lane 15 = jejunum; lane 16 = ileum; lane $17=$ colon; lane $18=$ cecum; lane $19=$ rectum; lane 20 = testis; lane 21 = epididymis; lane 22 = sublingual gland; lane $23=$ submandibular gland; lane 24 = thyroid; lane 25 = adrenal gland; lane 26 = thymus; lane $27=$ pituitary; lane 28 = prostate gland; lane $29=$ lymph nodes; lane 30 = skin; lane $31=$ muscle. The $18 S$ ribosomal RNA expression level was used as the internal control. 


\section{DISCUSSION}

It has been reported that LT $\beta R$ does not only help trigger apoptosis and lead to the release of the cytokine interleukin 8 , but it is also essential for the development and organization of the secondary lymphoid organs and chemokine release (Chang et al., 2002). Thus, this study will provide the molecular basis for identifying genetic variations in the $L T \beta R$ gene and the primary foundation for understanding the mechanisms of LT $\beta R$ in porcine tissues. In this study, the full-length coding sequence of the $L T \beta R$ gene was isolated from S. scrofa. The coding sequence of $L T \beta R$ was shown to have 1266 nucleotides encoding a protein of 421 residues with a molecular weight of $45.61 \mathrm{kDa}$ and a $\mathrm{pI}$ of 5.71 .

The TNFR superfamily members have been found to contain 6 conserved cystein domains in their N-terminal regions (Armitage, 1994), which allow formation of an extended rod-like structure that is responsible for ligand binding (Banner et al., 1993). Bioinformatic analysis indicated that the LT $\beta$ R protein contains a signal peptide and a TNFR domain. LT $\beta$ R specifically binds the lymphotoxin membrane form (a complex of LT- $\alpha / \beta$; Crowe et al., 1994) within this domain. This is consistent with previous studies of mice LT $\beta$ R (Force et al., 1995; Nakamura et al., 1995). Therefore, we speculate that the porcine LT $\beta$ R can also be directed to the extracellular by the signal peptide and trigger multiple signal transduction by binding to TNF-like cytokines.

The molecular mechanism by which actors bind to the LT $\beta$ R protein remains a central unresolved problem for biochemists and pharmacologists owing to the absence of clear structural data. Homology modeling of the porcine LT $\beta$ R protein was carried out using the $4 \mathrm{fhq}$ complex domain as a template (Altschul et al., 1997).

This may provide a basis for further studying the relationship between the structure and function of LT $\beta R$.

The AA sequences of $S$. scrofa $L T \beta R$ had 82.9, 82.4, 81.3, 80.5, 78.7, 74.6, and 73.0\% identity with the homologous sequences of E. caballus, C. lupus, A. melanoleuca, O. cuniculus, B. taurus, M. musculus, and H. sapiens. The evolutionary relationship based on LT $\beta \mathrm{R}$ AA sequences revealed that $S$. scrofa was more closely related to E. caballus, C. lupus, and A. melanoleuca. This implies that the function of the porcine LT $\beta$ R protein is only minimally divergent from that of the other species. Therefore, the study of porcine LT $\beta R$ can be used as a reference for understanding the function of this gene in other species.

$L T \beta R$ is expressed in most cell types, including the cells of the fibroblast, epithelial, and myeloid lineages but not those of the T or B lymphocytes. The expression patterns of porcine $L T \beta R$ in 31 tissues were analyzed using RT-PCR, and the results showed that gene expression was high in the prostate, submandibular, and adrenal glands; moderate in the pituitary, kidney, cerebellum, duodenum, brain, testis, thyroid, muscle, liver, lung, sublingual gland, heart, spinal cord, epididymis, thymus, and lymph node; low in the brainstem, hypothalamus, skin, jejunum, and cecum; and almost nonexistent in the esophagus, rectum, pancreas, colon, ileum, spleen, and stomach. The different expression patterns in the different tissues may be related to the differential regulation of LT $\beta R$ in those tissues. Compared to the differential expression patterns of $L T \beta R$ mRNAs in mouse tissues, those of porcine $L T \beta R$ mRNAs were notably different (Nakamura et al., 1995). For example, $L T \beta R$ expression of swine was moderate in the brain, thymus, and lymph node; however, in the same tissues of mice, expression was low. To further explain the observed differential expressions of the gene, additional research is necessary. 
In conclusion, we isolated porcine $L T \beta R$ and performed sequence and tissue transcription profile analyses. The findings presented herein have established the primary foundation for further insights into the structure and function of $L T \beta R$.

\title{
ACKNOWLEDGMENTS
}

\author{
and \#31460580).
}

\section{REFERENCES}

Altschul SF, Madden TL, Schaffer AA, Zhang J, et al. (1997). Gapped BLAST and PSI-BLAST: a new generation of protein database search programs. Nucleic Acids Res. 25: 3389-3402.

Armitage RJ (1994). Tumor necrosis factor receptor superfamily members and their ligands. Curr. Opin. Immunol. 6: 407-413.

Arnold K, Bordoli L, Kopp J and Schwede T (2006). The SWISS-MODEL workspace: a web-based environment for protein structure homology modelling. Bioinformatics 22: 195-201.

Banner DW, D'Arcy A, Janes W, Gentz R, et al. (1993). Crystal structure of the soluble human $55 \mathrm{kd}$ TNF receptor-human TNF beta complex: implications for TNF receptor activation. Cell 73: 431-445.

Beutler B and Van Huffel C (1994). Unraveling function in the TNF ligand and receptor families. Science 264: 667-668.

Chang YH, Hsieh SL, Chen MC and Lin WW (2002). Lymphotoxin beta receptor induces interleukin 8 gene expression via NF-kappaB and AP-1 activation. Exp. Cell Res. 278: 166-174.

Crowe PD, VanArsdale TL, Walter BN, Ware CF, et al. (1994). A lymphotoxin-beta-specific receptor. Science 264: $707-$ 710.

Force WR, Walter BN, Hession C, Tizard R, et al. (1995). Mouse lymphotoxin-beta receptor. Molecular genetics, ligand binding, and expression. J. Immunol. 155: 5280-5288.

Gill RM, Coleman NM and Hunt JS (2007). Differential cellular expression of LIGHT and its receptors in early gestation human placentas. J. Reprod. Immunol. 74: 1-6.

Guex N and Peitsch MC (1997). SWISS-MODEL and the Swiss-PdbViewer: an environment for comparative protein modeling. Electrophoresis 18: 2714-2723.

Marsters SA, Ayres TM, Skubatch M, Gray CL, et al. (1997). Herpesvirus entry mediator, a member of the tumor necrosis factor receptor (TNFR) family, interacts with members of the TNFR-associated factor family and activates the transcription factors NF-kappaB and AP-1. J. Biol. Chem. 272: 14029-14032.

Moller S, Croning MD and Apweiler R (2001). Evaluation of methods for the prediction of membrane spanning regions. Bioinformatics 17: 646-653.

Nakamura T, Tashiro K, Nazarea M, Nakano T, et al. (1995). The murine lymphotoxin-beta receptor cDNA: isolation by the signal sequence trap and chromosomal mapping. Genomics 30: 312-319.

Nakano H, Oshima H, Chung W, Williams-Abbott L, et al. (1996). TRAF5, an activator of NF-kappaB and putative signal transducer for the lymphotoxin-beta receptor. J. Biol. Chem. 271: 14661-14664.

Remouchamps C, Boutaffala L, Ganeff C and Dejardin E (2011). Biology and signal transduction pathways of the Lymphotoxin-alphabeta/LTbetaR system. Cytokine Growth Factor Rev. 22: 301-310.

Rooney IA, Butrovich KD, Glass AA, Borboroglu S, et al. (2000). The lymphotoxin-beta receptor is necessary and sufficient for LIGHT-mediated apoptosis of tumor cells. J. Biol. Chem. 275: 14307-14315.

Schwede T, Kopp J, Guex N and Peitsch MC (2003). SWISS-MODEL: An automated protein homology-modeling server. Nucleic Acids Res. 31: 3381-3385.

Smith CA, Farrah T and Goodwin RG (1994). The TNF receptor superfamily of cellular and viral proteins: activation, costimulation, and death. Cell 76: 959-962.

Tracey KJ and Cerami A (1994). Tumor necrosis factor: a pleiotropic cytokine and therapeutic target. Annu. Rev. Med. 45: 491-503.

VanArsdale TL, VanArsdale SL, Force WR, Walter BN, et al. (1997). Lymphotoxin-beta receptor signaling complex: role of tumor necrosis factor receptor-associated factor 3 recruitment in cell death and activation of nuclear factor kappaB. Proc. Natl. Acad. Sci. U. S. A. 94: 2460-2465. 
Vondenhoff MF, Kraal G and Mebius RE (2007). Lymphoid organogenesis in brief. Eur. J. Immunol. 37 (Suppl 1): S46-S52.

Wimmer N, Heigl U, Klingseisen L, Schneider-Brachert W, et al. (2013). Lymphotoxin-beta receptor signalling regulates cytokine expression via TRIM30alpha in a TRAF3-dependent manner. Mol. Immunol. 54: 40-47.

Wu MY, Wang PY, Han SH and Hsieh SL (1999). The cytoplasmic domain of the lymphotoxin-beta receptor mediates cell death in HeLa cells. J. Biol. Chem. 274: 11868-11873. 